\title{
The Leap of Comparative Advantage Trap in Guangzhou-Based on the Perspective of Global Value Chain
}

\author{
Ji-Yan Wu ${ }^{1}$, Zi-Jian Luo ${ }^{1} \&$ Zhi-Huang Huang ${ }^{1}$ \\ ${ }^{1}$ Finance Department of International Business School, Jinan University, Qianshan Road 206\#, Zhuhai City, Guangdong \\ Province, China \\ Correspondence: Ji-Yan Wu, Finance Department of International Business School, Jinan University, Qianshan Road \\ 206\#, Zhuhai City, Guangdong Province, China.
}

Received: November 21, 2018

Accepted: December 5, $2018 \quad$ Available online: December 14, 2018

doi:10.11114/aef.v6i1.3784

URL: https://doi.org/10.11114/aef.v6i1.3784

\begin{abstract}
This paper analyzes the situation and reasons of the trap of comparative advantage in Guangzhou, and proposes some strategies on how to leap the trap of comparative advantage. Firstly, based on the perspective of global value chain, this paper analyzes the status of Guangzhou in the global value chain through RCA (revealed comparative advantage index) and RTV (revealed technology added value index), and illustrates the situation of Guangzhou in the trap of comparative advantage. Secondly, the reasons why Guangzhou is into comparative advantage trap are analyzed from three aspects, capital, labor force and technology. Thirdly, in view of the main reasons, we seek some effective strategies to leap the comparative advantage trap, promote the transformation and upgrading of enterprises in guangzhou into innovative enterprises, and lead to the promotion of the competitiveness of Guangzhou in the globalization division of labor.
\end{abstract}

Keywords: comparative advantage trap, global value chain, competitive advantage

\section{Introduction}

The GaWC ranking is not a ranking of the city's economic competitiveness. It indicates the location of a city in the world's urban cities network by verifying the economies and both professional and innovative knowledge flows between cities. This list is considered to be the world's most authoritative ranking of world cities. GaWC divides cities with their unique perspectives to show the city's position and integration in the global economy. In 2017, the global city rankings compiled by the Globalization and World Cities (GaWC) research network was released. Guangzhou ranked 27 th in the world's first-tier cities. Since the adoption of the reform and opening up, the Guangzhou economy has undergone earth-shaking changes. In 2018, Shenzhen had also become a world first-tier city. It can be seen that Guangzhou has developed rapidly through its long history and manufacturing advantages. It has developed rapidly in recent decades, mainly using abundant labor, introducing foreign capital, and vigorously developing labor-intensive export processing industries. As a new city, Shenzhen City, through continuous introduction of technology and capital, develops its economy at a high speed, seizes opportunities in the reform and opening up, and constantly catches up with the development of Guangzhou.

Influenced by the theory of comparative advantage, Guangzhou has been vigorously developing labor-intensive industries in the past few decades, which has driven the economic development of Guangzhou. However, due to the rising labor and land resource costs, economic development cannot rely entirely on labor-intensive industries; moreover, due to the lower labor cost in Vietnam and other southeast Asian countries, Guangzhou gradually lost its comparative advantage and failed to achieve industrial transformation and upgrading, thus falling into the trap of comparative advantage. Once caught in the trap of comparative advantage, the industrial structure of a city cannot be upgraded, which will lead to the outflow of talent and slow economic growth.

Guangzhou and Shenzhen, as the only two cities in Guangdong province in the global first-tier ranking, have far exceeded other cities in Guangdong province in economic development and are the key force in the China's economic development. Guangzhou has long been the core city of Guangdong's economic development. But in recent years, the emerging city, Shenzhen, has begun to catch up with Guangzhou. Compared with Shenzhen, Guangzhou has the following three deficiencies in terms of technological innovation. First, the concept of urban development in Guangzhou is outdated and the industrial structure is solidified. 95 percent of the industries in Guangzhou are the 
traditional industry, and only 5 percent of the industries are the advanced manufacturing industry. However, 70.91 percent of the industries in Shenzhen are the advanced manufacturing industry, and only 29.09 percent of the industries are the traditional industry. Second, Guangzhou innovation capital investment is insufficient. The proportion of R\&D expenditure to GDP is an important indicator. In 2016, Guangzhou's R\&D expenditure was 45.1 billion Yuan, and R\&D expenditure accounted for only $2.3 \%$ of GDP. However, Shenzhen's R\&D expenditure reached 80 billion Yuan, accounting for $4.1 \%$ of GDP. Meanwhile, Guangzhou's R\&D expenditure was 45.1 billion Yuan, and R\&D expenditure accounted for only $2.3 \%$ of GDP. Third, the rate of science and technology advantage conversion is small in Guangzhou. Guangzhou had many universities and research institutions, and scientific research institutions and universities accounted for $70 \%$ of the province, but these technological advantages had not been translated into scientific and technological achievements. Although the number of scientific and technological personnel and scientific research institutions in Shenzhen is not as large as that in Guangzhou, it is far ahead of Guangzhou in terms of technological innovation.

This paper analyzes the situation and reasons of the trap of comparative advantage in Guangzhou, and proposes some strategies on how to leap the trap of comparative advantage. Firstly, based on the perspective of global value chain, this paper analyzes the status of Guangzhou in the global value chain through RCA (revealed comparative advantage index) and RTV (revealed technology added value index), and illustrates the situation of Guangzhou in the trap of comparative advantage. Secondly, the reasons why Guangzhou is into comparative advantage trap are analyzed from three aspects, capital labor force and technology. Thirdly, in view of the main reasons, we seek some effective strategies to leap the comparative advantage trap, promote the transformation and upgrading of enterprises in Guangzhou into innovative enterprises, and lead to the promotion of the competitiveness of Guangzhou in the globalization division of labor.

\section{Literature Review}

\subsection{The Meaning of the Comparative Advantage Trap}

The comparative advantage trap refers to the fact that a country (especially a developing country) produces and exports primary products and labor-intensive products in full accordance with comparative advantages, and is in an international economy with developed countries that mainly export technology and capital-intensive products. Although it can benefit from the trade, the trade structure is unstable and the country is always at a disadvantage, thus falling into the trap of comparative advantage.

After carding the theory of comparative advantage and its policy application debate, Wang Nuobei and Duan Yuan (Wang.N.B.\&Duan.Y., 2009) explained why the development of comparative advantage theory had positive effect for countries to convert their comparative advantages, improve their industrial structure, and develop national competitive advantage. Affected by the theory of comparative advantage, Guangzhou vigorously develops comparative advantage industries to boost economy according to its comparative advantage. But in recent years, Guangzhou gradually found that the speed of economic development relying on comparative advantage began to decrease. Ma Yushan (Ma.Y., 2013) analyzed the current situation of China foreign trade through RCA (Revealed Comparative Advantage Index), indicating that China still followed the principle of comparative advantage but the results were not optimistic. Some suggestions were pointed out for improving the structure of foreign trade development. RCA (revealed comparative advantage index) well illustrates the current situation of the country's comparative advantage. This paper adopts this method to scientifically show the situation of Guangzhou's comparative advantage and analyzes the reasons of the comparative trap. Yang Wenshuang and Liu Xiaojing (Yang.W.S.\&Liu.X.J., 2018) used Markov chain analysis method to analyze the liquidity of industrial comparative advantage in Northeast China in detail, and concluded that economic development in Northeast China must rely on industrial upgrading. He indicated that the biggest difficulty in industrial upgrading was advantageous solidification in the traditional industries and lacking innovation in the developing process. The specific analysis of northeast China shows that the region caught in the trap of comparative advantage is limited by technological innovation, and the industry cannot be upgraded and transformed, which will lead to slow economic development

In short, the comparative advantage trap illustrates a situation that countries or regions will fall deeply into the trap of comparative advantage when they continue developing their industries which are considered as the comparative advantage for a long time. Technological innovation is the key force for the region to overcome the trap of comparative advantage

\subsection{The Meaning of the Global Value Chain}

As for the theory of global value chain, according to Sadler (Sadler, 2002), global value chains are the combination of activities that create value from the design process to the end of life. This kind of product-centered production organization activities between countries attach great importance to the value-added links in the product chain, and also attach great importance to the interaction and benefit distribution among enterprises in the value chain. 
By studying a large amount of literature, this paper considers that the global value chain is the sum of all activities from the source of raw material to the final product. By analyzing the position of global value chain, we can learn the advantages and disadvantages of a certain industry in a certain region under the global division of labor. Li Dunrui (Li.D., 2018) believes that large-scale international industrial transfer and active participation in the international division of labor have changed China's backwardness, but from the perspective of the new division of labor in modern industry, China is still in a relatively unfavorable position. This paper believes that Guangzhou's position in the global value chain is at the middle and lower level. To transform and upgrade the current industry, it is necessary to inject new industry vitality under the global division of labor, promote the flow of product elements, and use high technology to promote the development of new industries to achieve the leap of comparative advantage trap.

\subsection{The Leap of Comparative Advantage Traps-competitive Advantage}

Competitive advantage mainly refers to the advantage that a company or country can make profits or benefits more than other enterprises or countries in some aspect, mainly due to technology, management, brand, labor cost and so on.

Zhang Chong (Zhang.C., 2013) analyzed the current situation of China's comparative advantage and proposed that China should introduce a competitive advantage strategy based on comparative advantage, transform comparative advantage into competitive advantage, and promote trade development through innovation. Compared to developing comparative advantage, developing competitive advantage emphasizes the importance of technological innovation and technological progress to industrial upgrading and transformation. This paper holds that the main reason for the difficulties in the industrial transformation of Guangzhou is the outdated concept of development. If we still follow the theory of comparative advantage, we will only fall into the trap of comparative advantage. Therefore, we need a new concept to guide our development. The transformation of comparative advantage into competitive advantage is a new concept to adapt to the development of modern economy. Song Aiping (Song A.P., 2016) analyzed the general situation of China's foreign trade development under the guidance of comparative advantage theory, and found out the problems existing in China's economic development, and proposed how to transform from comparative advantage theory to competitive advantage theory to achieve the transformation and upgrading of China's foreign trade industrial structure. This paper thinks that the research on the development of China's foreign trade provides key guidance for regional industrial transformation and upgrading. Similar to the industrial structure transformation of foreign trade, the industrial transformation and upgrading of Guangzhou needs technological innovation and progress. Liu Zaiqi and Wang Manli (Liu.Z.Q\&Wang.M.L., 2018) analyzed the export data of the countries in the sample from 1995 to 2014 through the overall network analysis method, indicating that the global economy presented a trend of specialized production, and a country's good institutional environment helped it to overcome the comparative advantage trap. The paper believes that a good institutional environment not only guarantees a stable order of national economic development, but also contributes to technological innovation and capital inflow.

To sum up, the key to realize the leap of the trap of comparative advantage lies in the transformation of comparative advantage into competitive advantage. Technological innovation and capital inflow are conducive to avoiding the trap of comparative advantage, forming a healthy economic development structure and achieving steady economic development.

\section{Theory and Model Preparation}

\subsection{Model Selection}

Hummels (Hummels, 2001) calculated the vertical specialization level index by input-output data, and pointed out that the larger the index value, the deeper the vertical specialization of the country in the international trade. Qi Jun-yan (Qi.J.Y. 2009) illustrated that Chinese products were mainly concentrated in low technology and low added value through the calculation of technical content and added value. And it showed that why it is difficult to upgrade China's industrial structure. Antràs (Antràs, 2012) proposed the upstream index, which measures the country's position in the global value chain. Yang Jing-jing, Yu Yi and Wang Hua (Yang.J., Yu.Y.\&Wang.H., 2013) calculated RTV to explain the export situation of each province, which showed that strengthening the building of infrastructure can reduce the negative impact of natural resource endowment on export complexity. Zhu Jun-guo (Zhu.J.G., 2017) measured the status of global value chains from different angles and got different results. Wang Peng-liang (Wang.P.L., 2017) combined the technology added value, the revealed comparative advantage index, the revealed comparative disadvantage index, the trade complementarity index and the trade combination index to conduct a qualitative analysis of the Sino-Australian trade structure, and proposed recommendations to improve the bilateral trade structure.

Guangzhou's industrial structure is mainly concentrated in labor-intensive and low-tech industries thought studying a large amount of literature, and it is difficult to transform and upgrade the dilemma of industries. Nowadays, there is no literature to analyze the relevant problems about the measurement of Guangzhou's product structure and global value chain status. At present, most scholars use the input-output method to calculate the upstream and downstream degrees, 
which indicating the status of a region in the global value chain. The input-output method needs to collect the input and output data of the trade region. This paper mainly studies Guangzhou's division of labor in the global value chain, since the data of the municipal statistical yearbook is before 2012. Because the calculation results are not convincing, this paper does not adopt the traditional input-output method.

Technology added value has been gradually cited in recent years. Technology added value, refers to the part of the added value of the exported products that belongs to the technical input. RTV (Revealed Technology Added Value Index) refers to the measurement of technology added value in a region whose export product has a comparative advantage. The greater RTV, the larger the technical content of the product, the higher the profit margin of the product.

\subsection{Symbol Description}

Table 1. Symbol Description

\begin{tabular}{c|l}
\hline Symbol & \\
\hline $\mathrm{X}_{\mathrm{ii}}$ & The exports of $\mathrm{j}$ product in $\mathrm{i}$ country \\
$\alpha_{\mathrm{ii}}$ & The proportion of $\mathrm{j}$ product exports to the total export value of $\mathrm{i}$ region \\
$\beta_{\mathrm{i}}$ & The proportion of the total exports of $\mathrm{j}$ product in all regions to the total exports in all regions \\
$\mathrm{RCA}_{\mathrm{ii}}$ & Revealed comparative advantage of $\mathrm{j}$ product in i region \\
$\mathrm{n}$ & The number of main regions in China \\
$\mathrm{m}$ & The number of products \\
$\mathrm{W}_{\mathrm{ii}}$ & The revealed comparative advantage weight of $\mathrm{j}$ product in i region \\
$\mathrm{RTV}_{\mathrm{ii}}$ & The revealed technology added value index of $\mathrm{j}$ product \\
$\mathrm{Y}_{\mathrm{i}}$ & The per capita GDP of i region \\
\hline $3.3 \mathrm{Model}$
\end{tabular}
3.3 Model Establishment and Illustrate

RTV (Revealed Technology Added Value Index) is mainly reflected in the weighted average of the exporting region's per capita GDP, and the weight is the proportion of RCA (Revealed Comparative Advantage Index) of the exporting country's exporting product in the RCA of the product in all regions.

Step 1. Calculation of the export share:

$$
\begin{gathered}
\alpha_{i j}=\frac{X_{i j}}{\sum_{i=1}^{m} X_{i j}} \\
\beta_{j}=\frac{\sum_{i=1}^{n} X_{i j}}{\sum_{i=1}^{n} \sum_{j=1}^{m} X_{i j}}
\end{gathered}
$$

Exports value can be divided into original trade and processing trade according to the nature of trade. Original trade refers to trade in the general sense, that is, the export of goods made from domestic raw materials, materials or technologies, or the import of goods made in foreign countries. Processing trade can be divided into two forms of Processing and Assembly Trade and Processing Trade for Imported Material. Processing and Assembly Trade means that all or part of raw materials, materials, auxiliary materials, components, supporting parts and packaging materials are provided by foreign companies. If necessary, equipment is provided. The processing units are processed and assembled according to the requirements of foreign companies, and the finished products are handed over to foreign investors. For sales, labor payment is charged. Processing Trade for Imported Material refers to enterprises with import and export management rights, which use foreign currency to purchase imported raw materials, materials, auxiliary materials, components, accessories and packaging materials after processing finished products or semi-finished products for export and export business. Therefore, the technical content of the Processing Trade for Imported Material will be higher than that of Processing and Assembly Trade.

Step 2. Calculation of the revealed comparative advantage index:

$$
\operatorname{RCA}_{\mathrm{ij}}=\frac{\alpha_{\mathrm{ij}}}{\beta_{\mathrm{j}}}
$$

When the RCA is greater than 1, which means the proportion of exports of the goods in the region to all exports in the region is greater than the proportion of the world's exports of such commodities to the total exports of all commodities. It illustrates that the region has the revealed comparative advantage to export the goods, which means that the region has an international competitiveness on the commodity. When the RCA is less than 1, it indicates that the region shows weak competitiveness in exporting the commodity. When the RCA is close to 1 , it indicates that the region has a relatively neutral status in exporting the commodity.

Step 3. Calculation of the weight:

$$
w_{i j}=\frac{\mathrm{RCA}_{\mathrm{ij}}}{\sum_{\mathrm{i}=1}^{\mathrm{n}} \mathrm{RCA}_{\mathrm{ij}}}
$$

Step 4. Calculation of the revealed technology added value index: 


$$
\mathrm{RTV}_{\mathrm{ij}}=\sum_{\mathrm{i}=1}^{\mathrm{n}} \mathrm{w}_{\mathrm{ij}} \ln \left(\mathrm{Y}_{\mathrm{i}}\right)
$$

By calculating the logarithm, it can reduce data fluctuations, thereby reducing influence from other factors.

The larger the RTV, it indicates that the export product has higher technical content and is in an upstream position in international trade.

\section{Analysis of the Situation of Guangzhou's Comparative Advantage Trap}

The economic and trade pattern of the world has increased developing countries' role in the global production chain. In the global value chain, the upstream is mainly developed countries whose production are attached to the high-tech, in order to exchange technology for high profits. The regions in the midstream and downstream, participate the world trade with low labor costs and benefit from increasing commodity prices. At present, many developing countries are still in the downstream of the global value chain. When the developing countries engaging in low-tech activities, the competitive advantage is easy to lose, and it takes a lot of effort to climb up the upstream of the value chain. This paper firstly uses the revealed technology added value index to measure Guangzhou's position in the global value chain, which illustrates the current situation of the comparative advantage trap in Guangzhou.

\subsection{Analysis of Guangzhou's Global Value Chain Status-Based on Revealed Technology Added Value Index (RTV)}

This paper collects 2017 related data, including the per capita GDP and export value, according to the official ranking data of the latest per capita GDP in the top 11 provinces and cities.

Table 2. Revealed Comparative Advantage Index (RCA)

\begin{tabular}{cccc}
\hline RCA & Original trade & Processing and Assembly Trade & Processing Trade for Imported Material \\
\hline Guangzhou & 0.90 & 1.72 & 1.02 \\
Shenzhen & 1.06 & 0.20 & 1.07 \\
Shanghai & 0.88 & 1.38 & 0.45 \\
Beijing & 1.08 & 2.98 & 1.26 \\
Jiangsu & 0.89 & 0.65 & 0.30 \\
Zhejiang & 1.51 & 0.12 & 0.59 \\
Fujian & 1.31 & 0.39 & 0.87 \\
Shandong & 1.10 & 0.75 & 1.57 \\
Chongqing & 0.75 & 0.39 & 0.57 \\
Jilin & 1.25 & 1.00 & 2.07 \\
Shanxi & 0.50 & 0.07 & 0.99 \\
\hline Average & 1.02 & 0.88 & .
\end{tabular}

From the RCA values of the three trades in Guangzhou in Table 2, it can be seen that the RCA of Processing and Assembly Trade is far superior to the other two trades, and the RCA value of Original trade is lower than the other two trades. Both of above illustrate that Guangzhou's trade mainly relies on the Processing and Assembly Trade to gain profits, Guangzhou is in a downstream position in the global value chain and in an unequal position in international trade.

Compared with other cities, it can be seen that the RCA value of Processing and Assembly Trade of Guangzhou has reached 1.72, far exceeding most of the regions, which indicates that Guangzhou has a strong comparative advantage in international trade. It is due to the large number of labor population, and the industry development mainly follows the theory of comparative advantage. In addition, the RCA of Original trade is below average, indicating that Guangzhou's comparative advantage in technology and capital is not obvious, or even at a disadvantage. 


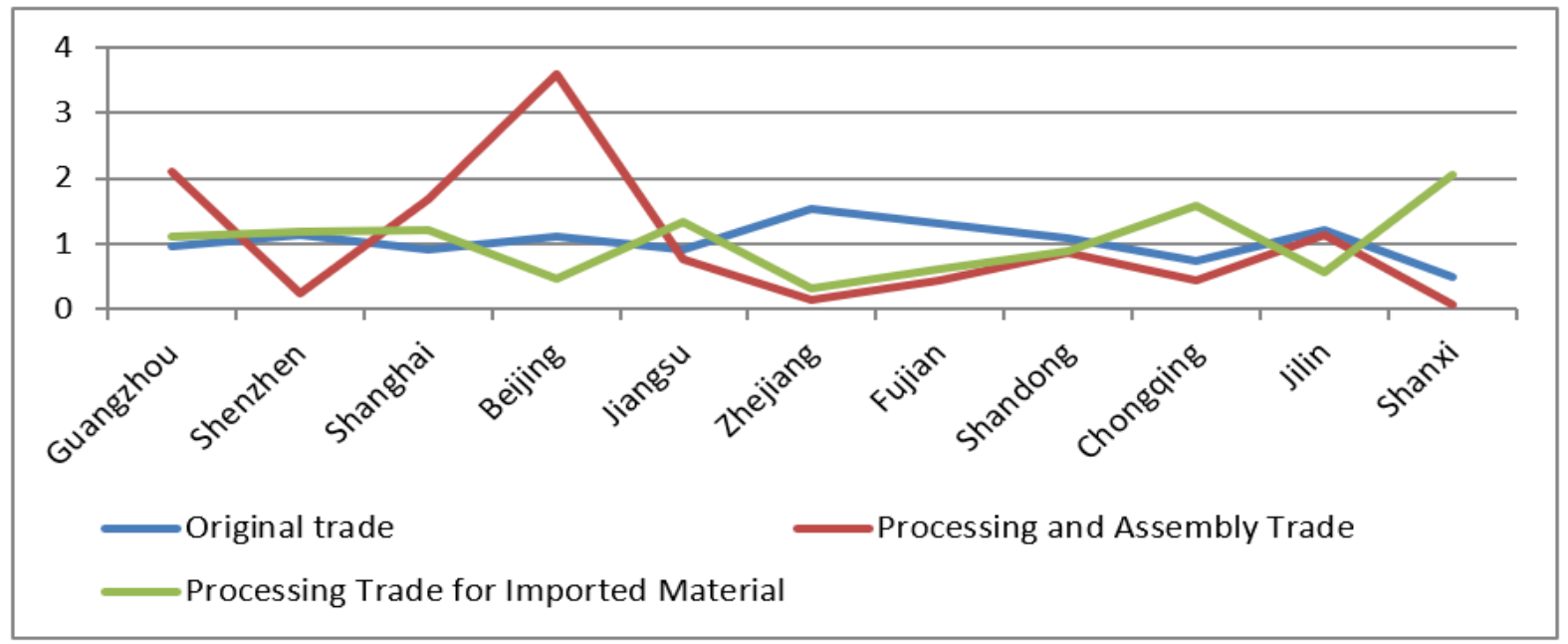

Figure 1. Technology added value distribution comparison chart

Combine the calculated data and Figure 1, Guangzhou's RTV of Processing and Assembly Trade reached 2.11, Processing and Assembly Trade accounting for $50.4 \%$ of several major industries. Moreover, compared with Shenzhen, the RTV value of processing materials is 8.79 times that of Shenzhen, and the RTV values of the other two trades are lower than that of Shenzhen. Although Guangzhou is the most economically developed region in Guangdong Province, Guangzhou's position in the global value chain is significantly lower than that in Shenzhen. Compared with other regions, the Processing Trade industry occupies most of the industrial structure of Guangzhou. The added value obtained through Processing Trade accounts for nearly $78 \%$ of the profits of Guangzhou. It can be seen that the current economic development of Guangzhou is mostly derived from low-margin processing trade enterprises and the comparative advantage of Guangzhou is very obvious.

It can be seen from Figure 1 that the RTV value of Guangzhou's Processing and Assembly Trade is higher than that of most economically developed cities in China, while the Original Trade and Processing Trade for Imported Material does not show comparative advantages. Although the GDP performance is strong, but the profit rate is not high, the companies can only earn a small amount of processing costs. In the industrial structure of the input factors, the companies over-reliance on the labor factor and cannot rationally use capital and technology with high profits.

\subsection{Conclusion}

In the global value chain, the upstream regions will use high technology to obtain higher profits. In the midstream and downstream regions can obtain only small profits. The data shows that the profit margin of processing trade enterprises in Guangzhou is generally low, most of them are below 5\%, while the processing trade enterprises in Shenzhen are close to $10 \%$. This shows that the large processing trade enterprises in Guangzhou have lower profit margins, the enterprises mainly relying on the labor factor as a production factor to obtain an increase in the added value of products. Shenzhen City mainly replaces labor input through capital investment and technology investment to obtain higher profits.

For Guangzhou, it is still in the downstream of the global value chain, which due to the deep-rooted processing trade industry formed in the past few decades. Although the economic development is very stable, Guangzhou mainly relies on low labor costs to achieve product added value in the global value chain. Under the trend of globalization, such industries are no longer suitable for future development, and there is an urgent need to upgrade the industry and optimize the structure.

If Guangzhou does not achieve industrial upgrading in the future and still follows the theory of comparative advantage based on labor, as a result, Guangzhou would fall into a trap of comparative advantage, which will lead to the industry's inability to develop healthily, limit economic development and gradually lose its comparative advantage in international trade.

In order to change Guangzhou's position in the global value chain and climb from the downstream to the upstream, it is necessary to turn comparative advantage into competitive advantage. The key is to transform from a labor-intensive industry to a capital-intensive industry.

\section{Analysis of the Cause of Guangzhou's Comparative Advantage Trap}

This paper believes that the main reason that affects Guangzhou's trap of comparative advantage is the influence of production factors. Due to the unreasonable application of the three main production factors of labor, capital and 
technology, the products lose their competitiveness and cannot change from comparative advantage to competitive advantage, which leads to a comparative advantage trap. This part mainly analyzes the factors of production and explains the reasons for the comparative advantage trap by discussing fundamental issues.

\subsection{Labor}

From the perspective of global value chain, Guangzhou has the comparative advantage of low labor cost. Guangzhou follows the theory of comparative advantage and mainly develops labor-intensive industries. Recently, the labor cost in Guangzhou has been rising, and the comparative advantage of labor costs in Guangzhou has gradually weakened. In recent years, the competitiveness of labor-intensive industries in developing countries has increased, especially in Southeast Asia, where labor costs are lower than in China, and many foreign-invested companies like Nike have moved to other countries. Nowadays, many positions require increasing knowledge and skills, and many workers are unable to make their own human capital investment. As a result, their comparative advantages are gradually weakened. If Guangzhou continues to follow the comparative advantage of low labor costs to develop labor-intensive industries, it will fall into the trap of comparative advantage. The rise in labor costs has led to an increase in the cost of products, which has led to a decline in the competitiveness of products, making Guangzhou's labor-intensive enterprises lose their sustainable development capabilities.

The chart below shows the labor costs in Guangzhou in recent decades.

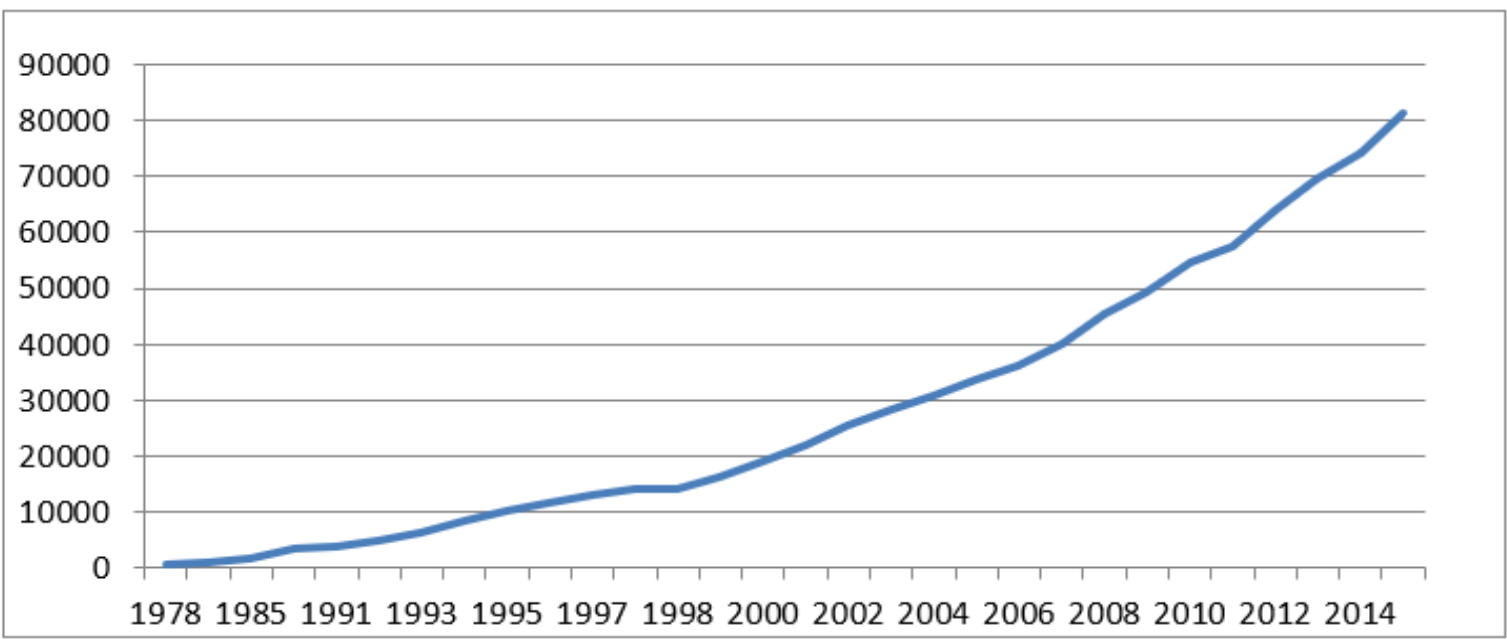

Figure 2. Average annual salary of employees in Guangzhou (unit: dollar)

It can be seen from Figure 2 that the average annual wage of employees in Guangzhou has been rising in recent decades, Showing an exponential upward trend. In particular, since the 21 st century, wages have risen even more dramatically, reflecting rising labor costs.

The rapid increase in wages in Guangzhou is due to the continuous improvement of labor productivity and the fact that the supply of labor is no longer unlimited supply, especially the working-age population tends to decrease. What's worse, the imbalance between supply and demand in China's labor market is not only reflected in the high-skilled labor force, but also in the low-end labor force. In 2004, the shortage of migrant workers in China's coastal areas reflected the shortage of low-end labor force. In order to compete for these scarce labors. Many companies have to maintain the existing labor force and attract more labor by means of raising salaries and welfare benefits. In this context, natural low-end labor compensation will continue to rise. Therefore, many scholars believe that the shortage of labor, especially the shortage of low-end labor, is an important factor in the rise of China's unit labor cost, which is caused by the continuous decline in the number of effective surplus labor in rural areas.

In the past, industrial development in Guangzhou relied mainly on labor production factors. In recent years, labor costs have risen. The continuous development of domestic financial markets has also increased capital liquidity and reduced capital costs. With the deepening of the global division of labor, the industrial structure in Guangzhou is in urgent need of transformation and upgrading. Therefore, it is necessary to introduce capital and technology to form a diversified industrial structure and commit to transforming processing trade enterprises into innovative enterprises.

\subsection{Capital}

Capital is the main driving force for the formation and development of industry. Generally speaking, the scale of capital input changes in the same direction as the development process of advanced industrial structure. The larger the scale of investment, the faster the process of advanced industrial structure development. In the global value chain perspective, 
countries with a comparative advantage in capital tend to be upstream of the global value chain and can achieve higher profits. However, Guangzhou does not have the comparative advantage of capital. It follows the comparative advantage of low labor cost and mainly develops labor-intensive industries, so it is easy to fall into the trap of comparative advantage. The use of more capital and the development of capital-intensive industries are effective ways for Guangzhou to leap the comparative advantage trap.

Foreign direct investment is the main way for Guangzhou to increase its capital stock. Both Shenzhen and Guangzhou have introduced a large number of foreign investment. But Shenzhen, which is also the first-tier city in the world, has better investment and use of capital than Guangzhou. Through the analysis of the foreign direct investment of the two cities usage, it can be concluded that the improper utilization of capital in Guangzhou is one of the reasons for the comparative advantage trap in Guangzhou. The following will analyze the dilemma of Guangzhou's current comparative advantage through the use of foreign investment in Guangzhou and Shenzhen.

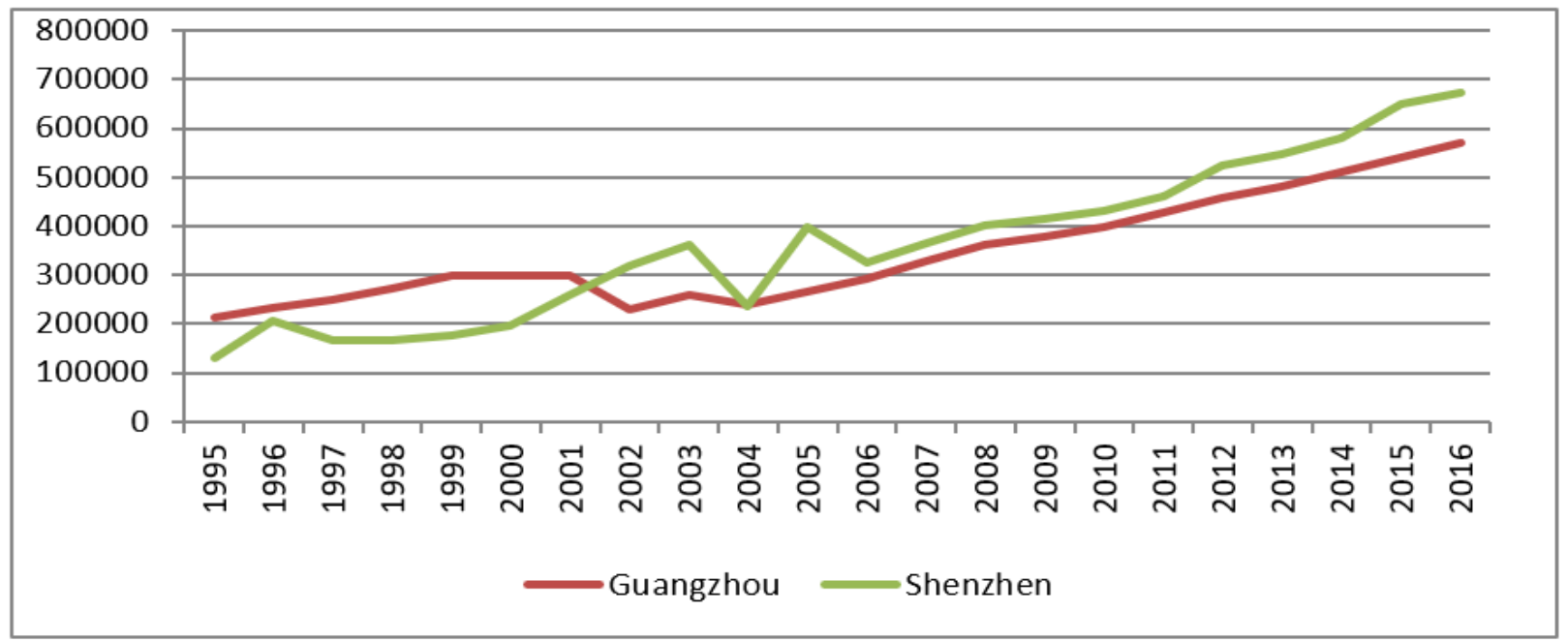

Figure 3. Guangzhou \& Shenzhen using FDI (Foreign Direct Investment) chart (unit: 10,000 US dollars)

In the previous analysis, Guangzhou's position in the global value chain was significantly lower than that in Shenzhen, and it was concluded that Guangzhou relied heavily on labor production factors in its industrial structure. As can be seen from Figure 3, before the 21st century, Guangzhou's use of FDI (Foreign Direct Investment) was significantly better than that of Shenzhen. But since 2004, even though FDI in both cities has shown a rising trend, Shenzhen has outgrown Guangzhou in terms of its use of capital, which is clearly better than Guangzhou. It shows that the current industry in Guangzhou does not reasonably use labor and capital. Under this circumstance, Guangzhou still follows the theory of comparative advantage, and it is easy to fall into the trap of comparative advantage in the face of industrial transformation and upgrading.

\subsection{Technology}

With the deepening of international division of labor and cooperation, the global industry has entered a production model based on knowledge and skills, technology research and development, and fund-raising investment. In fact, the production factor that can increase the added value of products is the ability of technological innovation. The main industry in Guangzhou is the processing and assembly trade industry, and the technical content is not high. In recent years, the output value of Shenzhen's advanced manufacturing industry is 2 3 times that of Guangzhou, and the number of talents introduced in Shenzhen is 8 9 times that of Guangzhou. In 2016, Guangzhou had 1.584 million professional and technical personnel, 160 scientific research institutions, and 25,432 employees in various scientific research institutions, including 18,514 scientific research personnel. In 2016, Shenzhen had 95,730 patents with valid invention patents, compared with 30,305 in Guangzhou. In terms of R\&D expenditures, Shenzhen's R\&D expenditure in 2016 reached 12 billion US dollars, accounting for 4.1\% of GDP. In 2016, Guangzhou's R\&D expenditure was about 6.56 billion US dollars, and R\&D expenditure was $2.3 \%$ of GDP. Although the number of scientific research institutions in Guangzhou far exceeds that of Shenzhen, the input-output ratio is far behind that of Shenzhen. According to the Guangzhou Yearbook (2017), in 2016, Guangzhou's foreign trade imports were 51.132 billion US dollars, and exports were 87.177 billion US dollars. In 2016, the export volume of high-tech products was 13.518 billion US dollars, accounting for $17.91 \%$ of the city's total exports.

After the reform and opening up, Guangzhou is committed to developing labor-intensive industries such as beverage processing and textiles. The long-term development of labor-intensive industries has made Guangzhou a middle and a 
lower level in the global value chain. Compared with developed countries, its trade status is at a disadvantage; its added value is low and its industry is relatively low-end. The development of technology-intensive industries in Guangzhou lags behind that of developed countries, and the core technologies are subject to these developed countries, and the products produced are low in technical content. Most of Guangzhou's export products lack international competitiveness and are of the same quality as most of the products in the market. Therefore, they have low profits in the competitive market and are in a passive position as "price receivers". The development of science and technology can effectively promote industrial transformation and upgrading. Therefore, the development of science and technology is a key factor for Guangzhou to leap the comparative advantage trap.

\section{Research on the Leaping Strategy of the Comparative Advantage Trap in Guangzhou}

The deep-rooted processing trade industry in Guangzhou faces the problem of transformation and upgrading. The key to achieving the leap of comparative advantage trap is that comparative advantage is transformed into competitive advantage.

(1) Economies of scale is the foundation of the transformation and upgrading. At present, Guangzhou has many enterprises, but the distribution of enterprises is too scattered and the integration of resources is insufficient, resulting in the industry cannot form scale effect. Enterprises in Guangzhou should use advanced machinery and equipment to cultivate professionals and improve labor, capital, and technology productivity. In addition, the entire production chain of the company should be diversified, that is, new innovations should be realized from raw material sources, processing and production, packaging and transportation, marketing, after-sales service, etc., and eventually expand market share and achieve economies of scale.

(2) Technological innovation and technological advancement are the key to the transformation of comparative advantage to competitive advantage. In recent years, the rise of Huawei company has been largely attributed to its technological input, which has led to the innovation and development of Shenzhen. The innovation and advancement of technology can firstly attract technology inflow through talent policy. Secondly, it can build a creative innovation park with unique characteristics of Guangzhou, and bring high-tech enterprises into a high-end industrial base similar to Zhongguancun. Finally, the advantages of university resources and scientific research institutions should be utilized. For example, more scientific and technological competitions like the climbing plan of Guangdong province and the Hong Kong-Zhuhai-Macao innovation competition should be held to promote talent cooperation, knowledge exchange and the development of high-tech enterprises in Guangdong province.

(3) Attract foreign investment, integrate global resources, and enhance the status of global value chains. Guangzhou has a profound cultural and historical heritage and has many hidden talents and development potential. Since the reform and opening up, it has attracted numerous enthusiastic young energies into Guangzhou. First of all, First of all, Guangzhou should attract overseas capital into local industries by improving financial market rules, accelerate the intra-industry turnover rate, and realize the rapid flow and accumulation of funds. Secondly, policies should be adopted to guide the development of multinational enterprises, and the upstream and downstream enterprises of global value chain should be utilized to build a complete industrial chain from source to customer, so as to realize rational utilization of resources. Finally, the intellectual property system and the supporting system of innovation results should be improved so that researchers can do scientific research with confidence and realize the industrial model with four characteristics: low resource consumption, high scientific and technological content, low environmental pollution and high economic efficiency.

\section{References}

Antràs, P., Chor, D., Fally, T., \& Hillberry, R. (2012). Measuring the Upstreamness of Production and Trade Flows. Cepr Discussion Papers, 102 (3), 1-49.

Hummels, D., Ishii, J., \& Yi, K. M. (2001). The Nature and Growth of Vertical Specialization in World Trade. Journal of International Economics, 54(1), 75-96. https://doi.org/10.1016/S0022-1996(00)00093-3

Li, D. R. (2018). Industrial transfer under the background of "Belt and Road" and the status of China's global value chain. Journal of Xi'an University of Finance and Economics, (09), 78-84.

Liu, Z. Q., \& Wang. M. L. (2018). "Comparative Advantage Trap” in Global Value Chains-Empirical Analysis Based on Overall Network and Country Panel Data. International Trade Issues, (03), 100-112.

Ma, Y. S. (2013). Comparative Advantages and Comparative Advantages of China's Foreign Trade. Journal of Kaifeng Education College, (09), 280-281.

Qi, J. Y. (2009). "Technology and Value-added Perspectives of Exports: A Re-examination of China's Trade Comparative Advantages and Competitiveness". Modern Finance and Economics, (07). 
Song, A. P. (2016). "Comparative Advantage" as "Competitive Advantage"-Thinking about the upgrading of China's foreign trade structure. Modern Commerce, (06), 74-75.

Wang, N. B., \& Duan, Y. (2009). A Comparative Review of Comparative Advantage Theory and Its Policy Application. East China Economic Management, (06), 139-142.

Wang, P. L. (2017). Research on Sino-Australian Bilateral Trade Structure-Based on Analysis of Technology Added Value. South China University of Technology, 20(04), 67.

Yang, J. J., Yu, Y., \& Wang, H. (2013). "Measurement of Export Technology Structure and Its Influencing Factors-Based on the Research of Provincial Panel Data". Finance and Trade Research, (04).

Yang, W. S., \& Liu, X. J. (2018). Research on "Comparative Advantage Trap" in Northeast China. Economic Issues, (03), 7-13.

Zhang, C. (2013). From comparative advantage to competitive advantage-the choice of China's trade model. China Securities and Futures, (03), 131-133.

Zhu, J. G. (2017). A review of the measurement of global value chain status and its influencing factors.

Knowledge-Power, (08), 1-3.

\section{Copyrights}

Copyright for this article is retained by the author(s), with first publication rights granted to the journal.

This is an open-access article distributed under the terms and conditions of the Creative Commons Attribution license which permits unrestricted use, distribution, and reproduction in any medium, provided the original work is properly cited. 